\title{
Optimal Design of the Propulsion System of a Hyperloop Capsule
}

\author{
Denis Tudor, Student Member, IEEE and Mario Paolone, Senior Member, IEEE
}

\begin{abstract}
In this paper, we focus on the assessment of the optimal design of the propulsion system of an energyautonomous Hyperloop capsule supplied by batteries. The novelty in this paper is to propose a sizing method for this specific transportation system, and answer the question whether the energy and power requirements of the Hyperloop propulsion are compatible with available power-electronics and battery technologies. By knowing the weight of a pre-determined payload to be transported along pre-determined trajectories, the proposed sizing method minimizes the total number of battery cells that supply the capsule's propulsion and maximizes its performance. The constraints embed numerically-tractable and discrete-time models of the main components of the electrical propulsion system and the battery, along with a kinematic model of the capsule. Although the optimization problem is non-convex due to the adopted discrete-time formulation, its constraints exhibit a good numerical tractability. After having determined multiple solutions, we identify the dominant ones by using specific metrics. These solutions identify propulsion systems characterized by energy reservoirs with an energy capacity in the order of 0.5 MWh and a power rating below 6.25 MW, and enable an energy consumption between 10-50 Wh/ $\mathrm{km} /$ passenger depending on the length of the trajectory.
\end{abstract}

Index terms - Hyperloop, transportation, batteries, energy conversion, optimization, optimal design, propulsion.

\section{NOMENCLATURE}

$\Delta i \quad$ Sampling time interval along the capsule's trajectory

$\Delta j \quad$ Sampling distance interval of the capsule's trajectory

$\eta \quad$ Efficiency of the capsule propulsion system (joint mechanical and electrical)

$\phi \quad$ Time constraint scaling up factor

$\rho \quad$ Hyperloop tube air density

a Capsule's acceleration

$C_{d} \quad$ Capsule drag coefficient

$C_{\text {batt }}$ Capacity of the battery

$C_{\text {cell }}$ Capacity of a cell

$F_{\text {drag }}$ Capsule drag force

$F_{\text {traction }}$ Capsule traction force

$i \quad$ Index of time associated to the position of the capsule along the trajectory

$I_{\text {batt }} \quad$ Battery current

$I_{\text {cell }} \quad$ Cell current

$j \quad$ Index of space associated to the position of the capsule along the trajectory

$k_{1} \quad$ Weight per unit power density of a linear induction motor

$k_{2} \quad$ Weight per unit power density of a power electronic converter

The authors are with École Polytechnique Fédérale de Lausanne, 1015 Lausanne, Switzerland. (e-mail: denis.tudor@epfl.ch).
$L \quad$ Total length of the capsule trajectory

$m \quad$ Total mass of the capsule

$m_{0} \quad$ Passive mass of the capsule

$m_{\text {active }}$ Active mass of the capsule

$m_{B E S S}$ Mass of the battery of the capsule

$m_{\text {cell }} \quad$ Mass of a battery cell

$m_{\text {mechanics }}$ Mechanical mass of the capsule

$m_{\text {payload }}$ Payload mass of the capsule

$m_{P S} \quad$ Mass of the capsule propulsion systems

$n \quad$ Number of trajectory zones

$N_{p} \quad$ Number of cells in parallel in the battery pack

$N_{s} \quad$ Number of cells in series in the battery pack

$P_{\text {batt }} \quad$ Accessible power of the battery at its terminals

$P_{\max C e l l}$ Maximum power provided by a battery cell

$P_{\max }$ Maximum electrical power of the capsule propulsion

$P_{\text {traction }}$ Capsule traction power

$R_{\text {batt }}$ Equivalent series resistance of the battery

$R_{\text {cell }} \quad$ Equivalent series resistance of a battery cell

$S \quad$ Cross section surface of the capsule

$\mathrm{SoC} \quad$ Battery state-of-charge

$S o C_{\text {final }}$ Battery state-of-charge at the end of the capsule trajectory

$v \quad$ Capsule's speed

$V_{\text {batt }} \quad$ Accessible voltage of the battery at its terminals

$V_{\text {cell }} \quad$ Accessible voltage of the cell at its terminals

$V_{O C V}^{b a t t}$ Open circuit voltage of the battery

$V_{O C V}^{c e l l}$ Open circuit voltage of the cell

$w$

Normalization factor in the objective of the sizing problem 


\section{INTRODUCTION}

Historically, most transportation systems were designed considering different boundary conditions and deployment scenarios. The definition of the characteristics of the energy reservoir that a given transportation system uses is particularly important, because this element determines whether the carrier of the system is energy-autonomous or not. For instance, electric trains (ETs) and electric vehicles (EVs), even if sharing similar propulsion systems (PSs), exploit energy reservoirs with very different characteristics. ETs rely on the quasiinfinite energy reservoir of power grids that, compared to the usual power required by the train propulsion systems, can be considered as a quasi-infinite source of power. Conversely, EVs rely on energy reservoirs (i.e., battery energy storage systems - BESS) characterized by limited gravimetric and volumetric energy and power densities. Hence, the design of these two transportation systems is radically different. Indeed, for ETs the energy reservoir does not translate into physical constraints that, on the contrary, need to be well stated for the design of an EV in order to maximize its travel distance [1].

It is also worth noting that, compared to other transportation systems directly supplied by fossil fuels, ETs and EVs represent the best solution for intra-continental travel in terms of average energy usage per passenger per $\mathrm{km}$, as well as for the $\mathrm{CO}_{2}$ emissions per passenger per $\mathrm{km}$ [2], [3] $(\mathrm{EV}$ : $97 \frac{\mathrm{Wh}}{\text { passenger } \cdot \mathrm{km}}$ [4], 45 $\frac{\mathrm{gCO}}{\text { passenger } \cdot \mathrm{km}}$ [5]; ET: $180 \frac{\mathrm{Wh}}{\text { passenger } \cdot \mathrm{km}}$ [6], $20 \frac{\mathrm{gCO}_{2}}{\text { passenger } \cdot \mathrm{km}}$ [7]). The two aforementioned transportation systems merge their characteristics when translated into the Hyperloop concept. The Hyperloop transportation system is composed of a constrained space characterized by a lowpressure environment (operated at $\approx 50 \mathrm{mbar}$ ), that is usually represented by tubes that also house a dedicated rail system responsible for the mechanical constraining of energyautonomous vehicles, henceforth called capsules, carrying a given payload. Capsules should be self-propelled and can use the tube's rail for guidance, magnetic levitation and propulsion purposes. For an average speed in the order of ten times larger than the EVs or ETs and a maximum speed in the order of the speed of sound, Hyperloop is expected to achieve average energy consumption in the range of: $30-90 \frac{\mathrm{Wh}}{\text { passenger } \cdot \mathrm{km}}$ [8] and $\mathrm{CO}_{2}$ emissions in the range of 5-20 $\frac{\mathrm{gCO} 2}{\text { passenger. } \mathrm{km}}$. The Hyperloop potentially presents the same advantages of ETs (high speed, low energy-consumption and $\mathrm{CO}_{2}$ emissions per passenger per $\mathrm{km}$ ) while being at the same time an energyautonomous system such as an EV. However, to carry a payload of a few tons on a capsule travelling at a maximum speed higher than $1000 \frac{\mathrm{km}}{\mathrm{h}}$, along trajectories of hundreds of kilometers with an acceleration comparable with standard passenger air crafts, there are two fundamental questions that need to be addressed: (i) are today's batteries, power-electronic converters and electrical motors compatible with the power and energy needs of this new transportation system? (ii) Are the Hyperloop energy consumptions and emissions compatible with these expectations? In this paper, we focus on providing quantitative replies to these two questions by proposing a specific optimal sizing framework.

Hyperloop capsules move between pre-determined point-to- point stations (Station A and Station B) and fixed trajectories in low-pressure tubes. As aforementioned, the pressure in Hyperloop tubes is pumped down to values to the order of 50 mbar or below (i.e., [9]), a condition that reduces drag forces and increases efficiency and maximum achievable speed (see Fig. 1).

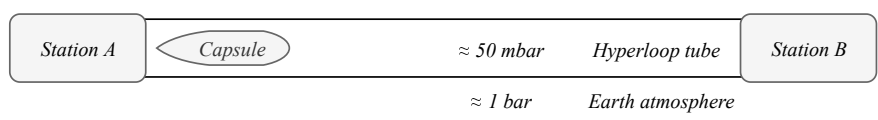

Fig. 1: The conceptual Hyperloop diagram.

This simple operational aspect substantially reduces the energy needs [10] of a Hyperloop capsule yet increases its maximum achievable speed. Consequently, the PS of a Hyperloop capsule can require a substantial amount of power (in the order of several MW per tens of tons of capsule mass [11]) to be extracted from an energy reservoir containing a relatively low amount of energy [3]. For this reason, the optimal sizing of the Hyperloop capsule PS is a non-trivial problem, which is the core of this paper.

The problem of the optimal sizing of energy-autonomous vehicles is studied in the existing literature, especially concerning EVs [1]. In [12], a modelling framework is proposed to study different aircraft-electric propulsion architectures by means of a platform that simulates power generation, distribution, and fuel consumption. Regarding the study of the behaviour of batteries in electric and hybrid vehicles, in [13], it is proposed a simulator specifically created in order to predict the state-of-charge (SoC) and dynamic behavior of different battery types. In [14], [15] and [16]- [19], optimization strategies and component sizing methods have been proposed to enhance the energy consumption of different energy autonomous vehicles. [17], [20]- [22] present optimization methods for electrical or hybrid vehicles; these methods especially involve BESSs.

However, none of the aforementioned papers focused on the specific problem of sizing the propulsion system of a Hyperloop capsule. In this respect, the novelty of the paper is set up by proving that with current technologies on batteries, power electronics and electrical machines, an energy-autonomous Hyperloop capsule is feasible, and more efficient in terms of energy consumption and $\mathrm{CO}_{2}$ emissions comparing with today's transportation systems.

By making use of numerically tractable models of electrical PSs and BESSs, we focus first on the formulation of a nonconvex optimization problem that targets the optimal design of the PS of a Hyperloop capsule. Our proposed optimization minimizes a bi-objective function where the first term is represented by the total number of the BESS cells and the second term-the norm- 2 of the discrete sampled accelerations along the capsule's trajectory. The constraints representing the capsule kinematic are also taken into account, as well as a regenerative braking. We provide a comprehensive analysis of the results for different weights of the terms in the objective function and identify dominant solutions by using specific metrics. We also present a sensitivity analysis of the identified dominant solution with respect to variations of parameters that 
can exhibit changes in the design stage of the capsule as well as for different lengths of the capsule trajectory.

The structure of the paper is the following: in Section II, we illustrate the hypotheses of the models adopted for representing elements of the capsule's PS and its kinematics. Then, we provide the formulation of the optimization problem to determine the fundamental characteristics of the capsule's PS. In Section III, we use the proposed optimization problem to design the PS of a capsule expected to travel along trajectories of different lengths and we discuss the results with a further sensitivity analysis with respect to parameters that can exhibit changes.

\section{HYPOTHESES AND PROBLEM STATEMENT}

\section{A. Trajectory}

The closed and sealed path of a Hyperloop is provided by an infrastructure composed of a tube or an underground tunnel. Indeed, confining the capsule into a sealed tunnel permits pumping down the pressure to values to the order of $5 \%$ (50mbar) of the standard atmosphere pressure [9].

As shown in Fig. 2, the total length of the trajectory is $L$ and it is split into $n$ different zones: $\left\{M_{1}, M_{2}, \ldots, M_{n}\right\}$, where $j$ represents the generic position of the capsule and $i$ the elapsed time relative to the generic discrete position, $j$. The capsule travels between $[0, L]$ where the trajectory is sampled at regular intervals, $\Delta j$, such that the discrete capsule position is $j=0,1, \ldots, \frac{L}{\Delta j}$. Since the capsule can move only in a single direction, forward, for each $j$ we can associate a corresponding discrete time index, $i\left(i=0, \ldots, t_{L_{k}}, \ldots, t_{L}\right.$ in correspondence of the zones $M_{1}, \ldots, M_{k}, \ldots, M_{n}$ ).
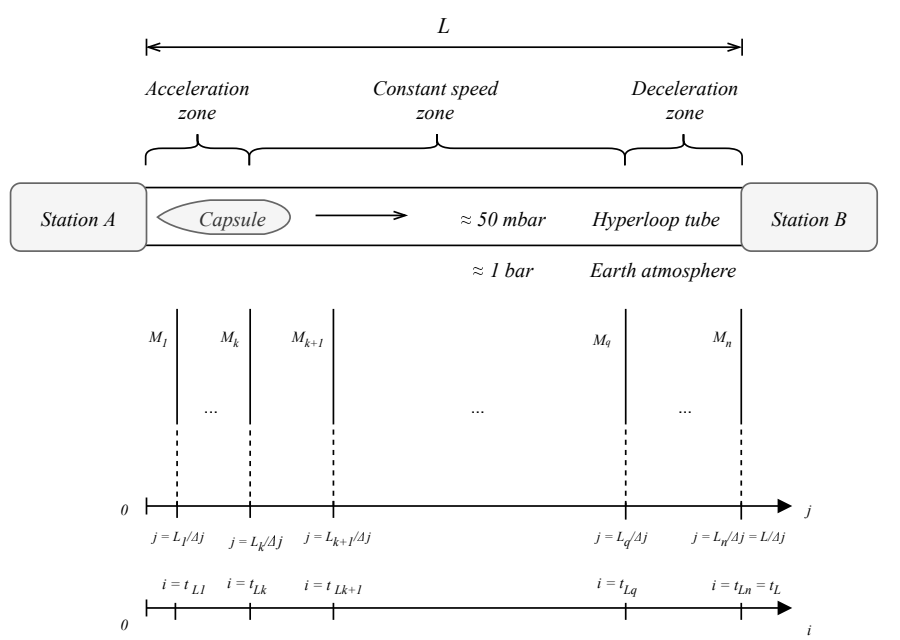

Fig. 2: The generic trajectory of a Hyperloop capsule.

The space budget of the trajectory for each of the $n$ zones (1) is pre-established by the designer due to the different geographical constraints of the trajectory (see Fig. 2).

$$
\left\{\begin{array}{c}
M_{1}, \forall j=0,1,2, \ldots, \frac{L_{1}}{\Delta j}-1 \\
M_{2}, \forall j=\frac{L_{1}}{\Delta j}, \frac{L_{1}}{\Delta j}+1, \ldots, \frac{L_{2}}{\Delta j}-1 \\
\ldots \\
M_{k}, \forall j=\frac{L_{k-1}}{\Delta j}, \ldots, \frac{L_{k}}{\Delta j}-1 \\
M_{k+1}, \forall j=\frac{L_{k}}{\Delta j}, \ldots, \frac{L_{k+1}}{\Delta j}-1 \\
\ldots \\
M_{n}, \forall j=\frac{L_{n-1}}{\Delta j}, \ldots, \frac{L}{\Delta j}
\end{array}\right.
$$

The trajectory is usually separated into typical zones such as: acceleration, constant speed and deceleration (see Fig. 2). The $M_{1}, \ldots, M_{k}$ zones are reserved for the acceleration, and zones $M_{k+1}, \ldots, M_{q}$ represent the constant speed ones (where the capsule achieves its maximum speed or the cruising speed). The last zones of the trajectory, $M_{q+1}, \ldots, M_{n}$, are used to brake the capsule before reaching the destination.

\section{B. The Model of the Capsule Propulsion System}

The architecture of the Hyperloop capsule PS is composed of three main components [19]: (i) an energy reservoir consisting of a BESS, (ii) a DC/AC power electronics converter and (iii) an electrical propulsion machine (e.g., a linear induction motor). In the following subsections, we present the models of these subsystems as they constitute some of the constraints of the targeted optimization problem.

1) Model of the capsule power source: There are different approaches to model the electric response of a battery cell, and the choice of the model depends on the complexity of the associated problem. In this respect, there are three main families of models [13], [24], [25]: (i) the so-called "bucket" models, where cells are represented as integral operators of charge/energy eventually by taking into account the associated charge/discharge efficiency, (ii) equivalent circuit models, where the voltage dynamics are simulated by means of an equivalent network of electric lumped components and where the $S o C$ is still modeled via an integral operator, and (iii) electrochemical models, where the cell's internal dynamics associated with ion species diffusion and electrochemical reactions are fully modeled. Due to the numerical complexity and large number of state variables required by the third type of cell models, in general, they cannot be directly used into an optimization problem. In this work, we adopt a cell model belonging to the second family. This choice is preferred as it enables us to derive a set of numerically tractable constraints capable of capturing the main cell's response. Fig. 3 shows the possible equivalent circuit of a cell where the charge diffusion dynamics are not taken into account [26] ${ }^{1}$. Below, we describe the cell's quantities.

- $V_{O C V}^{\text {cell }}$ : represents the open-circuit voltage of the cell, and it is a known function of the cell $S o C$ provided by the difference between the cells' electrodes' potentials [27].

- $I_{c e l l}$ : represents the current flowing through a single cell.

${ }^{1}$ The adoption of a multiple time constant model of the cell does not affect significantly the results as the time constant of the charge redistribution (in order of hours) is larger than the time spent by the capsule to complete the trajectory (several tens of minutes). For this reason, we prefer the use of the cell model shown in Fig. 3. 
- $R_{\text {cell }}$ : represents the equivalent series resistance of the cell. It also encompasses the equivalent resistance of the cell's terminals' connections with the next cell. $R_{\text {cell }}$ is assumed to be known and constant (e.g., we neglect its dependency on the cell's temperature) [28].

- $V_{\text {cell }}$ : corresponds to the voltage accessible in the correspondence of the cell's terminals; it is affected by the voltage drop produced by the $R_{\text {cell }}$.

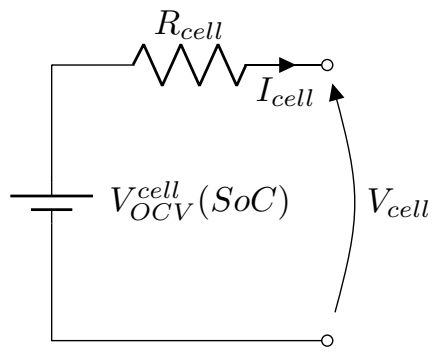

Fig. 3: Equivalent circuit of a cell adopted to derive the BESS constraints.

In a first approximation, the model of an entire BESS pack composed by identical cells can mathematically be described by (2), where $N_{s}$ and $N_{p}$ represent the number of series cells and the number of parallel cells of the BESS, respectively. $V_{O C V}^{\text {batt }}$ represents the open-circuit voltage, which is solely a function of the cells $S o C$; whereas $R_{b a t t}$ integrates the all the cells' and connectors' resistances. $C_{b a t t}$ represents the capacity of the BESS. $I_{b a t t}$ is the total current provided (or absorbed) by the BESS.

$$
\left\{\begin{array}{c}
V_{O C V}^{b a t t}=f(S o C) \\
V_{O C V}^{b a t t}=V_{O C V}^{c e l l} N_{S} \\
R_{b a t t}=R_{c e l l} \frac{N_{s}}{N_{p}} \\
I_{b a t t}=I_{\text {cell }} N_{p} \\
S o C=S o C(0)+\int_{0}^{t_{L}} \frac{I_{b a t t}}{C_{\text {batt }}} d t
\end{array}\right.
$$

Hence, $V_{b a t t}$ and $P_{b a t t}$, are the accessible voltage and power of the BESS (3).

$$
\left\{\begin{array}{c}
V_{\text {batt }}=N_{s}\left(V_{\text {OCV }}^{\text {cell }}-R_{\text {cell }} I_{\text {cell }}\right) \\
P_{\text {batt }}=I_{\text {batt }} V_{\text {batt }}
\end{array}\right.
$$

The function $V_{O C V}^{b a t t}(S o C)$ is usually available from the cell's manufacturer.

2) Propulsion: Speed and acceleration profiles are a function of the traction force provided by different types of electrical motors characterized by different performances.

For the ensemble of the electrical machine and converter, the most important parameters are

- $\frac{P}{P S_{\text {weight }}}$ which represents the ratio between the total amount of power per unit mass.

- $V_{D C}^{\max }$ which represents the maximum allowable DC voltage of the DC/AC converter.

\section{Capsule Kinematic Model}

We assume the capsule to be capable of carrying a payload mass defined by the designer, $m_{\text {payload. }}$ In order to parametrize the total mass of the capsule as a function of the problem's decision variables (that define the PS), we divide the total mass in two: a passive mass, $m_{0}$, and an active mass, $m_{\text {active }}$.

$$
m=m_{0}+m_{\text {active }}
$$

The passive mass represents the payload plus the mechanical sub-system masses, $m_{\text {mechanics }}$, such as the capsule's aeroshell, chassis, pressure vessels, stability mechanisms, braking mechanism and, if present, magnets for levitation.

$$
m_{0}=m_{\text {payload }}+m_{\text {mechanics }}
$$

The active mass includes the mass of the BESS, $m_{B E S S}$, plus the one of the motor and DC/AC converter, $m_{P S}$. The mass of the BESS is proportional to the product between $N_{s}$ and $N_{p}$ times the cell's mass, $m_{\text {cell }}$ (we assume that the cell mass is associated with cells' unitary mass plus cells' wiring and packaging).

Henceforth, we explicitly refer to the case of linear induction motors (LIM) [29]- [32] as this specific electrical machine is considered to be the best choice for energyautonomous Hyperloop capsules since it does not require the electrification of the rail. Another advantage of using a LIM in the architecture of a Hyperloop capsule is the maintenance procedure. With a contactless solution, PS periodical mechanicsmaintenance procedures may take place more rarely. Both aforementioned factors result in diminishing the price costs for the infrastructure and maintenance. We assume that the LIM is characterized by a given weight per unit power density $k_{1}$, and the voltage source inverter (VSI) to be characterized by a given weight per unit power density $k_{2}$. The total mass of the PS, $m_{P S}$, can then be simply linked to the maximum electrical power to be delivered along the trajectory for the capsule, $P_{\max }$, via (6) and (7) where $P_{L I M}$ and $P_{V S I}$ are the maximum powers of the LIM and VSI, respectively.

$$
\begin{gathered}
\left\{\begin{array}{c}
m_{\text {active }}=m_{B E S S}+m_{P S} \\
m_{B E S S}=N_{s} N_{p} m_{c e l l} \\
m_{P S}=P_{\max }\left(k_{1}+k_{2}\right)
\end{array}\right. \\
k_{1}=\frac{m_{L I M}}{P_{L I M}} ; k_{2}=\frac{m_{V S I}}{P_{V S I}}
\end{gathered}
$$

In order to express the mass of the PS as a function of the mechanical power provided to the capsule, we assume that the maximum power provided by the BESS is equal to the maximum power of the LIM and to the one of the VSI in order to optimize the performances of the PS [33]. Therefore, by introducing the transfer efficiency of the capsule PS, $\eta$, the mass $m_{P S}$ can be computed as in (8), where $P_{\text {max Cell }}$ is the maximum power provided by a cell that can be computed using (3).

$$
m_{P S}=\frac{1}{\eta} P_{\max C e l l} N_{s} N_{p}\left(k_{1}+k_{2}\right)
$$

Thus, the final expression of total mass is given by (9) where 


$$
\begin{aligned}
m & \sim N_{s} N_{p} . \\
& m=m_{0}+N_{s} N_{p} m_{\text {cell }}+\frac{1}{\eta} P_{\operatorname{maxCell}} N_{s} N_{p}\left(k_{1}+k_{2}\right)
\end{aligned}
$$

Throughout the trajectory, the capsule is represented by a kinematic model where the state variables are the acceleration, $a$, and speed, $v$, sampled along the trajectory (as shown in Fig. 2) with $\Delta j$, or time intervals $\Delta i$ corresponding to $\Delta j . \Delta i$ is computed with respect to $\Delta j$ through solving the associated equation: $\Delta j=v(j-1) \Delta i+\frac{1}{2} a(j) \Delta i^{2}$ required to have a uniform varied motion. The total length of the trajectory is $L$ and is divided, as in (1), into three main parts: acceleration, constant speed, and braking. Thus, the total number of discrete analysis points along the trajectory is $\left[\frac{L}{\Delta j}\right]$. Subsequently, the links of the discretized state variables of the capsule as a function of the power provided by the PS are derived.

One of the most significant advantages of the Hyperloop consists in the reduction of the drag force [34] as it is proportional to the fluid density $(\rho)$. Equation (10) provides the simplest expression of the drag force as a function of the generic position of the capsule along the trajectory, where $C_{d}$ represents the drag coefficient of the capsule and $S$ the cross section surface of the capsule.

$$
F_{\text {drag }}(j)=\frac{1}{2} S C_{d} \rho v(j)^{2}
$$

The PS traction force and traction power as a function of the generic capsule position along the trajectory are given by (11) and (12), respectively.

$$
\begin{aligned}
& F_{\text {traction }}(j)=m a(j)+F_{\text {drag }}(j) \\
& P_{\text {traction }}(j)=F_{\text {traction }}(j) \cdot v(j)
\end{aligned}
$$

By integrating (9), (10), (11) and (12), we obtain the following expression for the traction power, $P_{\text {traction }}$, as a function of $m, a$ and $v$.

$$
P_{\text {traction }}(j)=\left(m a(j)+F_{\text {drag }}(j)\right) \cdot v(j)
$$

Once reaching the maximum speed, $v_{\max }$ at $x_{v_{\max }}$, the instantaneous power consumption of the capsule is minimal and flattened due to (11). This simple observation, supported by the numerical results of Section III, permits us to state that the Hyperloop PS application is closer to a power-intensive application rather than an energy-intensive one. Still, due to the variation of $V_{\text {batt }}$ associated with the variations of the $S o C$ for a relatively long journey, the effect of depth-of-discharge $(D o D)$ on the $V_{O C V}^{\text {cell }}$ represents an element that should be taken into account in the problem formulation.

\section{Formulation of the Optimization Problem}

In view of the above-illustrated models of the capsule power-source, PS and kinematic model, we formulate the problem for the optimal design of the capsule PS as in (14).

$$
\begin{aligned}
& \min _{N_{s} N_{p}, a} \quad N_{s} N_{p}-w \cdot\|a\|_{2} \\
& \text { subject to } j=0,1,2, \ldots, \frac{L_{q}}{\Delta j}-1 \\
& v(j) \leq v_{\max } \\
& a_{\min _{M_{1}}} \leq a(j) \leq a_{\max _{M_{1}}}, \forall j=0,1,2, \ldots, \frac{L_{1}}{\Delta j}-1 \\
& a_{\min _{M_{q}}} \leq a(j) \leq a_{\max _{M_{q}}}, \forall j=\frac{L_{q-1}}{\Delta j}, \ldots, \frac{L_{q}}{\Delta j}-1 \\
& \frac{L^{2}}{\sum_{j=0}^{\frac{L}{\Delta j}} v(j) \cdot \Delta j} \leq T_{\max _{q}} \\
& P_{\text {traction }} \leq \eta P_{\text {batt }} \\
& S o C_{\min } \leq S o C \leq S o C_{\max } \\
& I_{\text {cell }}(j) \leq I_{\text {cellMax }} \\
& V_{O C V}^{\text {cell }}(0)=\left.V_{O C V}^{\text {cell }}\right|_{S o C=S o C_{\max }} \\
& V_{O C V}^{\text {batt }}=V_{O C V}^{c e l l} N_{S} \\
& R_{\text {batt }}=R_{\text {cell }} \frac{N_{s}}{N_{p}} \\
& I_{\text {batt }}=I_{\text {cell }} N_{p} \\
& C_{\text {batt }}=N_{p} C_{\text {cell }} \\
& S o C=S o C(0)+\sum_{i=1}^{t_{L}} \frac{I_{b a t t}}{C_{b a t t}} \Delta i \\
& \Delta i=\frac{-v(j-1)+\sqrt{v^{2}(j-1)+2 a \Delta j}}{a} \\
& V_{\text {batt }}=N_{s}\left(V_{O C V}^{\text {cell }}-R_{\text {cell }} I_{\text {cell }}\right) \\
& P_{\text {batt }}=I_{\text {batt }} V_{\text {batt }} \\
& m=m_{0}+m_{\text {active }} \\
& m_{0}=m_{\text {payload }}+m_{\text {mechanics }} \\
& m_{\text {active }}=m_{B E S S}+m_{P S} \\
& m_{B E S S}=N_{s} N_{p} m_{\text {cell }} ; m_{P S}=P_{\max }\left(k_{1}+k_{2}\right) \\
& k_{1}=\frac{m_{L I M}}{P_{L I M}} ; k_{2}=\frac{m_{V S I}}{P_{V S I}} \\
& m_{P S}=\frac{1}{\eta} P_{\operatorname{maxCell}} N_{s} N_{p}\left(k_{1}+k_{2}\right) \\
& m=m_{0}+N_{s} N_{p} m_{\text {cell }}+\frac{1}{\eta} P_{\max C e l l} N_{s} N_{p}\left(k_{1}+k_{2}\right) \\
& F_{\text {drag }}(j)=\frac{1}{2} S C_{d} \rho v(j)^{2} \\
& F_{\text {traction }}(j)=m a(j)+F_{\text {drag }}(j) \\
& P_{\text {traction }}(j)=\left(m a(j)+F_{\text {drag }}(j)\right) \cdot v(j)
\end{aligned}
$$

The objective function is composed of two elements: the weight of the BESS and the performance of the capsule represented by the norm- 2 of the array of the discrete accelerations sampled along the trajectory. We maximize $\|a\|_{2}$ as this value can be directly linked to the traveling time to complete the trajectory. Indeed, for the acceleration and 
constant-speed zones (that represent the large part of the trajectory), we know that $\frac{v(j+1)-v(j)}{\Delta i} \geq 0$, which also implies $\frac{v(j+1)-v(j)}{\Delta j} \geq 0, \forall j \leq \frac{L_{q}}{\Delta j}-1$. Therefore, we can say that

$$
\min \left(\frac{L^{2}}{\sum_{j=0}^{\frac{L}{\Delta j}} v(j) \cdot \Delta j}\right) \Longleftrightarrow \max \left(v_{\max }\right) .
$$

As $v_{\max }$ can be expressed as

$$
v_{\max }=\int_{t_{0}}^{t_{L_{k}}} a(\tau) d \tau \simeq \sum_{i=0}^{t_{L_{k}}} a(i) \Delta i,
$$

from (15) and (16), if we want to maximize $v_{\max }$, we have to maximize $\sum_{i=0}^{t_{L_{k}}} a(i) \Delta i$, which implies maximizing $|a|_{1}$. We choose to maximize the $\|a\|_{2}$ in order to give more weight to the higher values of the acceleration along the trajectory.

It is worth noting that, as $N_{s} N_{p}$ and $\|a\|_{2}$ in the objective function of (14) are different physical quantities, a weight factor, $w$, is necessary in order to normalize them.

It is worth observing that the constraints have explicitly considered that the maximum speed of the capsule cannot exceed a pre-determined value, $v_{\max }$, and that the average traveling time cannot be longer than a certain given threshold, $T_{\max _{q}}$ depending on the length of trajectory, $L$. Furthermore, the acceleration in the zones $M_{1}, M_{2}, \ldots, M_{k}$ are upper bounded by values compatible with airplanes acceleration profiles. We also constrained the $I_{\text {cell }}$ to be lower than the maximum admissible discharge rate of the considered cell. For the BESS, the $V_{O C V}^{\text {batt }}$ is initially chosen with respect to the railway electrification system standard. Finally, the $S o C$ should be in the safe range, bounded by $S o C_{\min }$ and $S o C_{\max }$ defined by the designer.

A final comment is about the deceleration stage performed in the zones $M_{q+1}, \ldots, M_{n}$. In these zones, the capsule actuates the braking: a dominant part of the deceleration is assumed to be produced by a dissipative braking mechanism, whereas a minimal part is assumed to be produced by a regenerative one [35], [36]. As the regenerative braking enables us to recover a minimal part of the capsule's kinetic energy limited by the maximum charging rate of the considered cell, $I_{\text {cellMax }}$ charge , it is not taken into account in the optimization problem. Therefore, in (14), the optimization problem is applied only for the acceleration and constant speed zones. However, in the numerical results, we charge the BESS in the zone $M_{q+1}, \ldots, M_{n}$

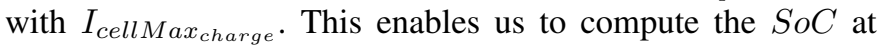
the end of the trajectory, $S o C_{\text {final }}$.

The problem (14) is non-convex due to the discrete nature of its equations as well as the $S o C$ expression. Indeed, in equation (2), the denominator of the integrating function (i.e. $C_{b a t t}$ ) is function of the control variable $N_{p}\left(C_{b a t t}=N_{p} C_{c e l l}\right)$. Since $I_{\text {batt }}$ and the $S o C$ are an internal and constrained variable of the problem, both dependent on the control variables, the constraint expressed through equation (2) is non-convex. The problem has been solved using a gradient-based method [37], [38], and we use first-order optimality conditions to determine whether a local minima has been identified. For the solution of a single problem corresponding to a given $w$ and a single set of $N_{s} N_{p}$ and $a$ initializations, we have got an average computational time of approximately 35 to 37 seconds using a standard laptop (3.5 GHz Intel Core i7 with 16 GB 2133 MHz LPDDR3 memory).

\section{NUMERICAL RESULTS}

\section{A. Assumptions on the Capsule Trajectory}

For a concrete example, the proposed optimization is applied to design the PS of a capsule expected to travel between the two largest cities in Switzerland: Geneva and Zürich ${ }^{2}$. The first length of the trajectory is $L=226 \mathrm{~km}^{3}$. In order to extensively validate the optimization process, other two lengths of the trajectory have been considered $L=500 \mathrm{~km}$ and $L=1000 \mathrm{~km}$.

The considered trajectories have been segmented in the zones reported in (17) for $L=226 \mathrm{~km}$, (18) for $L=500 \mathrm{~km}$ and (19) for $L=1000 \mathrm{~km}$, where $M_{1}$ and $M_{2}$ represent the acceleration zones, $M_{3}$ is the constant speed zone, and $M_{4}$ the deceleration one. The discrete sampling of the trajectory is $\Delta j=100 \mathrm{~m} . \Delta j$ has been chosen with two characteristics: (i) $\Delta j<<\min \left(L_{m}\right), \forall m=1,2, \ldots, n$ and (ii) determine an integer number of discrete points in order to have a coherent spatial sampling of the trajectory. To fix ideas, it results in a total number of 2260 discrete points for $L=226 \mathrm{~km}, 5000$ discrete points for $L=500 \mathrm{~km}$ and 10000 discrete points for $L=1000 \mathrm{~km}$.

$$
\begin{gathered}
\left\{\begin{array}{c}
M_{1}, \forall j=0,1,2, \ldots, \frac{L_{1}}{\Delta j}-1, \text { with } L_{1}=5 \mathrm{~km} \\
M_{2}, \forall j=\frac{L_{1}}{\Delta j}, \ldots, \frac{L_{2}}{\Delta j}-1, \text { with } L_{2}=26 \mathrm{~km} \\
M_{3}, \forall j=\frac{L_{2}}{\Delta j}, \ldots, \frac{L_{3}}{\Delta j}-1, \text { with } L_{3}=206 \mathrm{~km} \\
M_{4}, \forall j=\frac{L_{3}}{\Delta j}, \ldots, \frac{L}{\Delta j}, \text { with } L=226 \mathrm{~km}
\end{array}\right. \\
\left\{\begin{array}{c}
M_{1}, \forall j=0,1,2, \ldots, \frac{L_{1}}{\Delta j}-1, \text { with } L_{1}=5 \mathrm{~km} \\
M_{2}, \forall j=\frac{L_{1}}{\Delta j}, \ldots, \frac{L_{2}}{\Delta j}-1, \text { with } L_{2}=26 \mathrm{~km} \\
M_{3}, \forall j=\frac{L_{2}}{\Delta j}, \ldots, \frac{L_{3}}{\Delta j}-1, \text { with } L_{3}=480 \mathrm{~km} \\
M_{4}, \forall j=\frac{L_{3}}{\Delta j}, \ldots, \frac{L}{\Delta j}, \text { with } L=500 \mathrm{~km}
\end{array}\right. \\
\left\{\begin{array}{c}
M_{1}, \forall j=0,1,2, \ldots, \frac{L_{1}}{\Delta j}-1, \text { with } L_{1}=5 \mathrm{~km} \\
M_{2}, \forall j=\frac{L_{1}}{\Delta j}, \ldots, \frac{L_{2}}{\Delta j}-1, \text { with } L_{2}=26 \mathrm{~km} \\
M_{3}, \forall j=\frac{L_{2}}{\Delta j}, \ldots, \frac{L_{3}}{\Delta j}-1, \text { with } L_{3}=980 \mathrm{~km} \\
M_{4}, \forall j=\frac{L_{3}}{\Delta j}, \ldots, \frac{L}{\Delta j}, \text { with } L=1000 \mathrm{~km}
\end{array}\right.
\end{gathered}
$$

\section{B. Assumptions on the Capsule and PS}

The capsule is assumed to carry a payload mass equivalent to 25 persons (this payload might be replaced by a cargo one). The average mass payload attributed for a single person is $80 \mathrm{~kg}$, which means $m_{\text {payload }}=2000 \mathrm{~kg}$.

\footnotetext{
${ }^{2}$ The actual travel time between these two cities with the Swiss public train company is in the order of $2 \mathrm{~h} 30 \mathrm{~min}$, whereas time travel by plane is around 45 minutes (not including the boarding).

${ }^{3}$ Although this parameter is expected to influence the results of the optimization, the value we selected enables us to deploy a fast-charging strategy between subsequent stops of the capsule along a longer journey.
} 
1) Other general mechanical parameters: We assume the capsule to have a total mass of the mechanical sub-systems of $6000 \mathrm{~kg}$ (therefore, $m_{0}=8000 \mathrm{~kg}$ ), a frontal cross-section surface $S=6 m^{2}$ [39] and the value of the drag coefficient $C_{d}=0.1$ [40]. The aggregated efficiency of the LIM and VSI is also assumed to be $\eta=0.95$ [2].

The upper bounds for the accelerations in the stages $M_{1}$ and $M_{2}$ are selected to be in the same order of magnitude of maximum accelerations imposed by modern passenger aircrafts. In (20) we summarize the upper bounds for $M_{1}$ and $M_{2}$ (note that $g=9.81 \frac{\mathrm{m}}{\mathrm{s}^{2}}$ ), along with the maximum speed, $v_{\max }$, and maximum travel time $T_{\max _{q}}$. The maximum travel times are bounded by using the factor $\phi=\frac{L}{T_{\max }}{ }^{4}$ assumed to be equal to $11.3 \frac{\mathrm{km}}{\mathrm{min}}$.

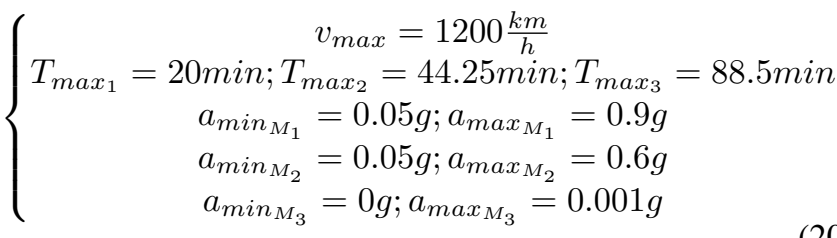

2) BESS: We assume the BESS to be composed by Lithium-Polymer NMC cells. In this respect, the numerical results of this section are inferred using a real cell, the Kokam SLPB 11543140H5. This specific cell was selected in view of its excellent power density and very-high discharge rate since these two are the most important cell characteristics for our application. More specifically, the cell can sustain a continuous discharge rate up to $30 \mathrm{C}$ and exhibits remarkable performance in terms of ageing (more than 1000 cycles at 90\% depth-ofdischarge). Its parameters have been fully characterized at the Authors' laboratory.

Concerning the maximum value for the $V_{O C V}^{b a t t}$, it was chosen based on "Railway applications - Supply voltages of traction systems" according to IEC 60850 standard [41]. Thereby, the values defined in (2) imply a $V_{O C V}^{\text {batt }}=1.5 \mathrm{kV}$ for $S o C_{\max }=100 \%$.

The constraints of the $S o C$ mark a safe operation zone of the BESS in order to guarantee that the cell will wear with the expected ageing and that they were selected according to the manufacturer's specifications. The cell-equivalent series resistance was measured at the Authors' laboratory at an operating temperature between $15-35^{\circ} \mathrm{C}$. Concerning the maximum discharge current, it also results from the cell capacity (5Ah) and maximum continuous discharge rate (30C). The charging current used by the regenerative braking is limited to $1 \mathrm{C}$. Also, this value is according to the manufacturer's data.

$$
\left\{\begin{array}{c}
S o C_{\max }=100 \% \\
S o C_{\min }=10 \% \\
R_{\text {cell }}=4.4 \mathrm{~m} \Omega \\
I_{\text {cellMax }}=150 \mathrm{~A} \\
I_{\text {cellMax }} \text { charge }_{\text {mat }}=5 \mathrm{~A}
\end{array}\right.
$$

3) Propulsion: The weight per unit power density of the LIM, $k_{1}$, is selected by making reference to a Hyperloop prototype developed in our laboratory whilst the same parameter

\footnotetext{
${ }^{4}$ The value of $\phi$ is defined by the designer/modeler.
}

for the VSI, $k_{2}$, was inferred using industrial-grade VSI used in the automotive sector.

$$
\left\{\begin{array}{l}
k_{1}=0.091 \frac{\mathrm{kg}}{\mathrm{kW}} \\
k_{2}=0.075 \frac{\mathrm{kg}}{\mathrm{kW}}
\end{array}\right.
$$

\section{Results}

Problem (14) was solved for the three different lengths of the trajectory, corresponding to three different average travel time constraints as shown in (20). For every length of the trajectory, Algorithm 1 is used in order to solve problem (14), where the normalization factor $w$ was varied from $10^{0}$ to $10^{8}$ in a decade-logarithmic way and, for each of its values, the control variables $N_{s} N_{p}$ and $a$ were initialized with different values (these initial values were selected in a range where they have a feasible technical meaning). An example for the behaviour of the problem objective, for $L=226 \mathrm{~km}$ and $w=100$, as a function of the initial values of $N_{s} N_{p, \text { init }}$ and $a_{\text {init }}$ is given in Fig. 4. We generated the solution space in Fig. 4 with the different initialization of $a$ and $N_{s} N_{p}$ for $w=100$ and $L=226 \mathrm{~km}$ by solving (14). This process was repeated for all the values of $w$ and $L$ where the white zone of the figure represents the minimum of the optimization problem (14). For the minimum point in Fig. 4 (identified within the white zone of the graph) we extract the corresponding trajectory information regarding the acceleration, speed, and time profiles, with respect to the position of the capsule and BESS status. The cluster of information found for each of the solutions contains all the necessary trajectory and system details of the capsule. The knowledge of the acceleration profile enables us to compute the speed profile (Fig. 5) along with the traction power profile (Fig. 6) and cell-current profile (Fig. 7) of the capsule.

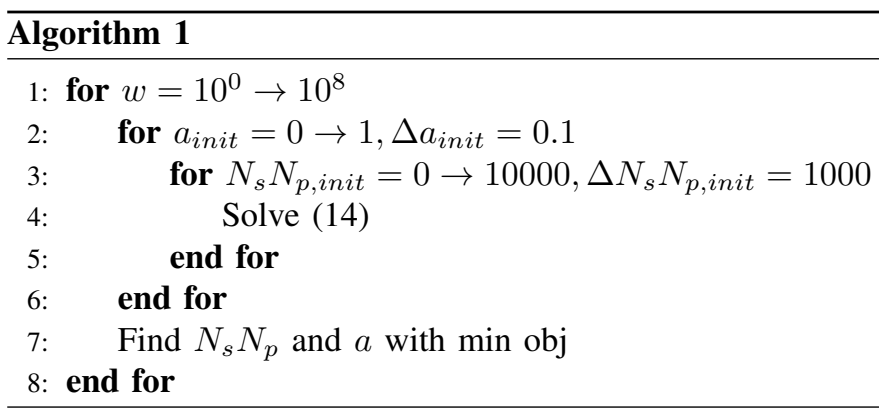

With Algorithm 1, the following figures show, for every length of the trajectory, $L$, the Pareto fronts of the most important capsule performance indicators and key parameters of the PS as a function of the normalization factor $w$. More specifically, Fig. 8 shows the values of the total number of cells of the BESS, Fig. 9 shows the capsule and the BESS masses, Fig. 10 and Fig. 11 show the maximum speed and acceleration achieved along the trajectory, Fig. 12 shows the maximum traction power, Fig. 13 shows the final $S o C$ of the BESS, $S o C_{\text {final }}$, and Fig. 14 shows the average time necessary to cover the trajectory. 


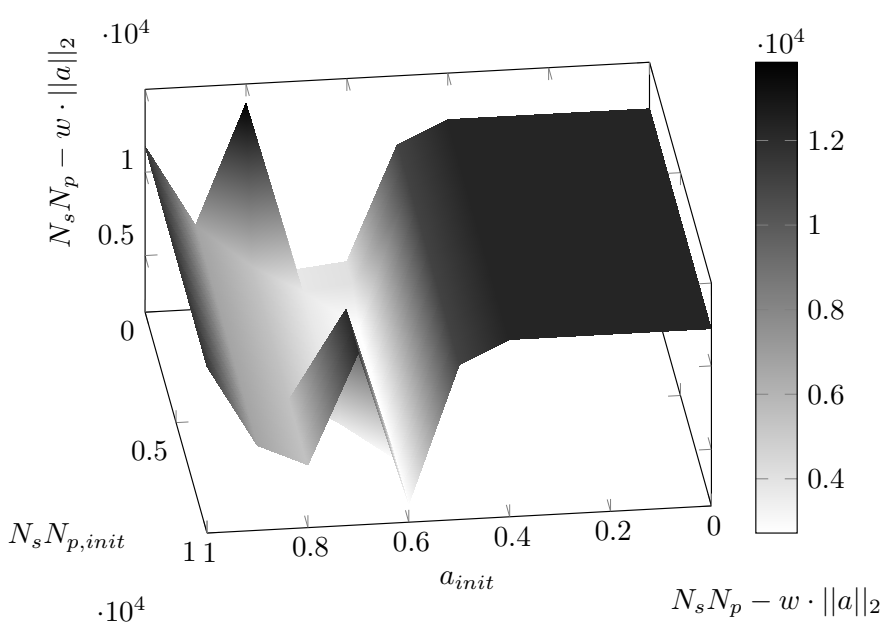

Fig. 4: Behaviour of the problem objective for $L=226 \mathrm{~km}$ and $w=100$ as a function of the initial values of $N_{s} N_{p, i n i t}$ and $a_{\text {init }}$.

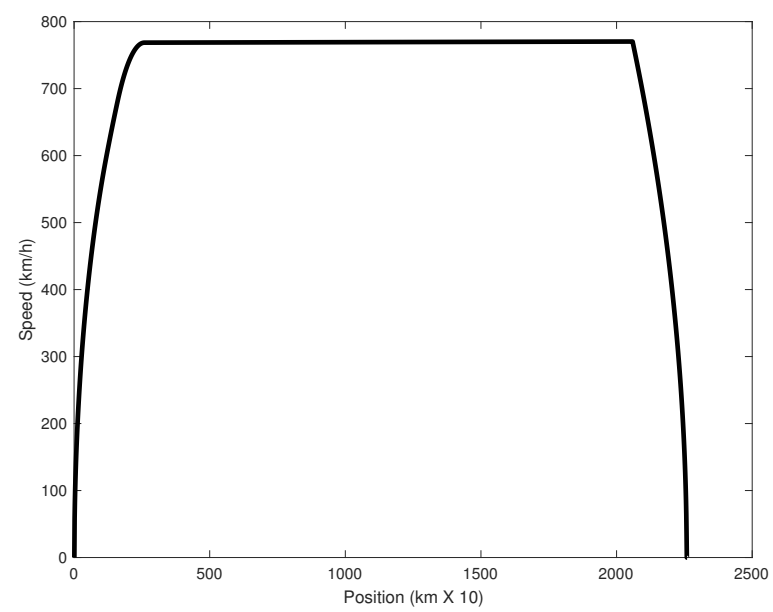

Fig. 5: Optimal-speed profile for $L=226 \mathrm{~km}, w=100$, $a_{\text {init }}=0.6 \frac{\mathrm{m}}{\mathrm{s}^{2}}, N_{s} N_{p, \text { init }}=2000 \mathrm{cells}$.

\section{General Observations}

As shown in Fig. 12, the maximum instantaneous power along the trajectory for the longer distances (i.e., $L=500 \mathrm{~km}$ and $L=1000 \mathrm{~km}$ ) is similar for the various solutions and in the range of 2 to $5.5 \mathrm{MW}$. For the shorter distance $(L=226 \mathrm{~km})$ the maximum power applied by the capsule's PS is, instead, larger due to two reasons: (i) the cruising speed (maximum speed) along the trajectory is smaller due to the amount of time that the capsule spends at that speed which enables minimizing the average traveling time, and (ii) the solutions of the optimization problem are governed by the $S o C$ constraint while the discharge rate and DoD of the cell are underused.

The normalization factor $w$ has, as expected, a substantial influence on the obtained optimal solutions. For relatively small values of $w \in\left[10^{0} ; 10^{2}\right]$, the maximum acceleration (see Fig. 11) is half of the maximum one imposed by a modern passenger aircraft. The corresponding BESS is not larger than

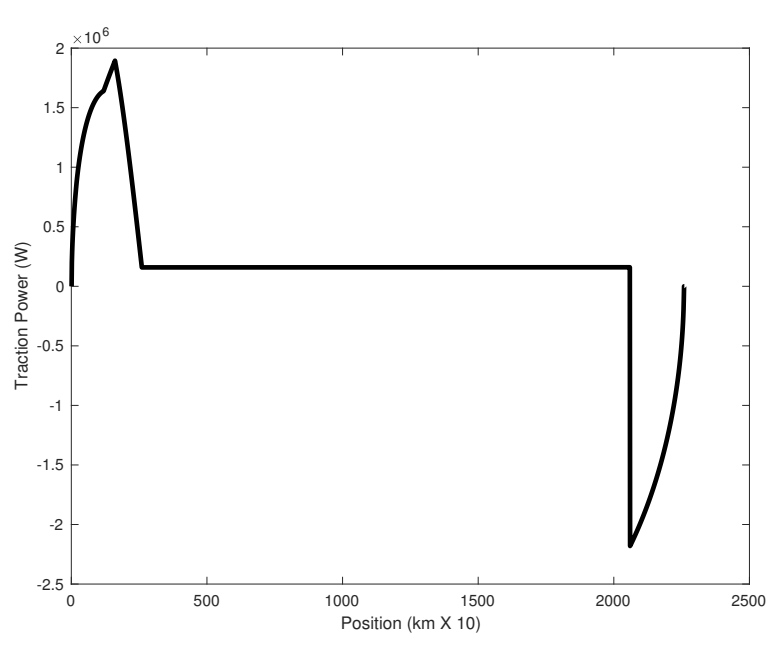

Fig. 6: Optimal traction-power profile for $L=226 \mathrm{~km}$, $w=100, a_{\text {init }}=0.6 \frac{\mathrm{m}}{\mathrm{s}^{2}}, N_{s} N_{p, \text { init }}=2000 \mathrm{cells}$.

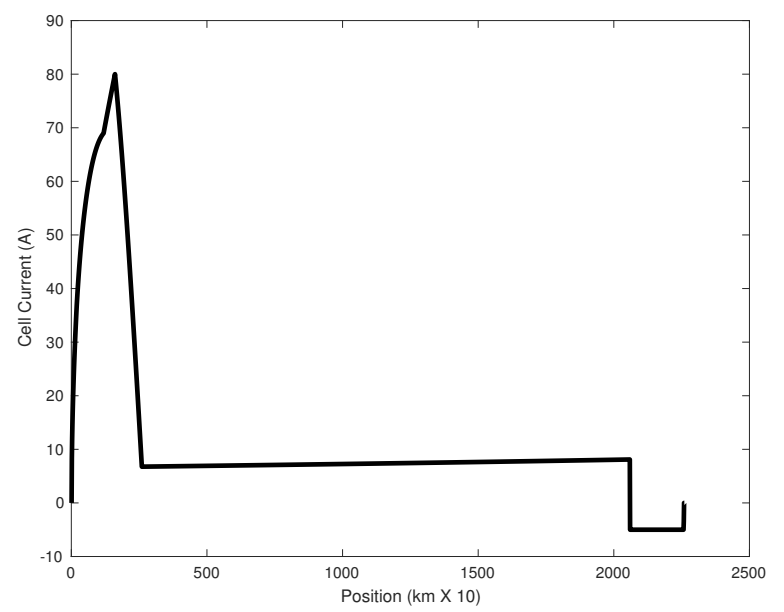

Fig. 7: Optimal cell-current profile for $L=226 \mathrm{~km}$, $w=100, a_{\text {init }}=0.6 \frac{m}{s^{2}}, N_{s} N_{p, \text { init }}=2000$ cells.

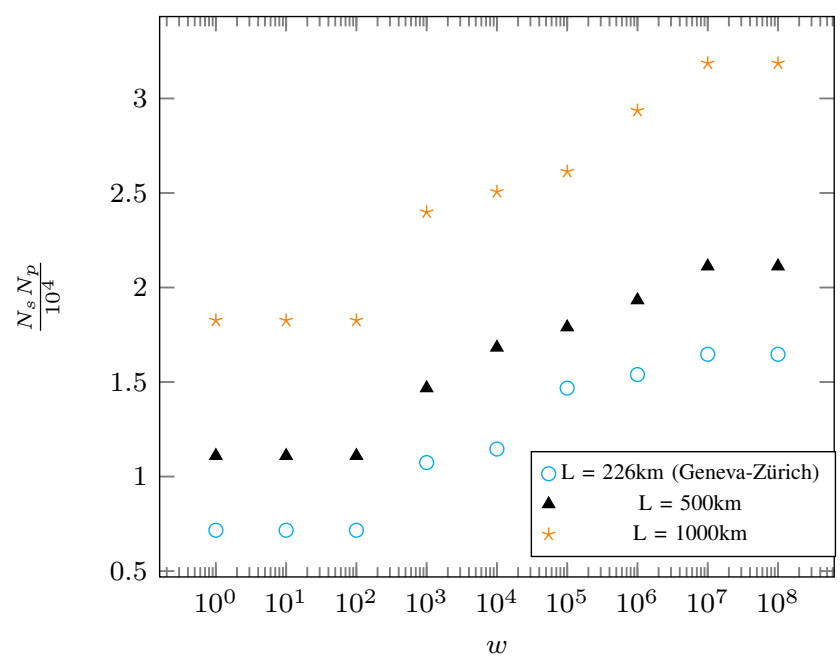

Fig. 8: Total number of cells of the BESS. 


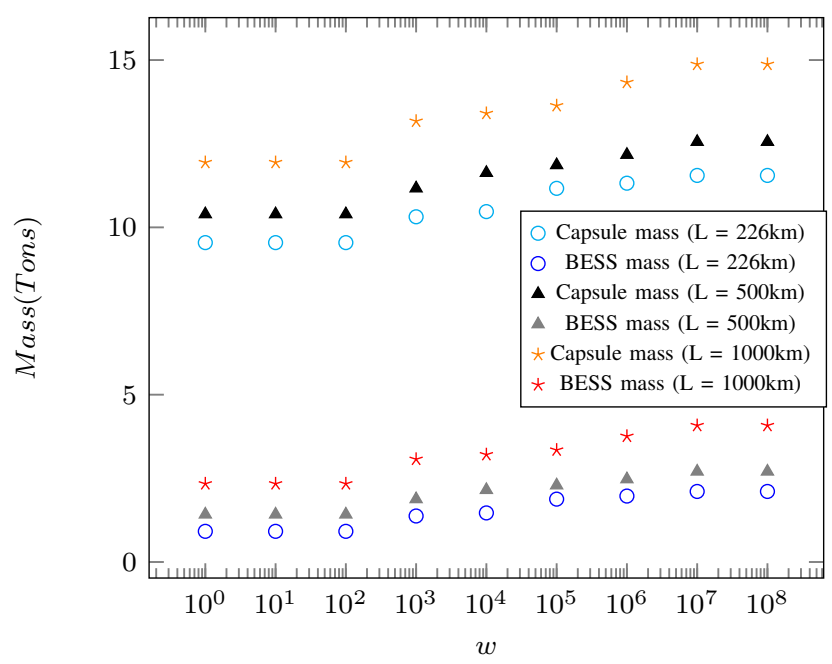

Fig. 9: Capsule and BESS masses.

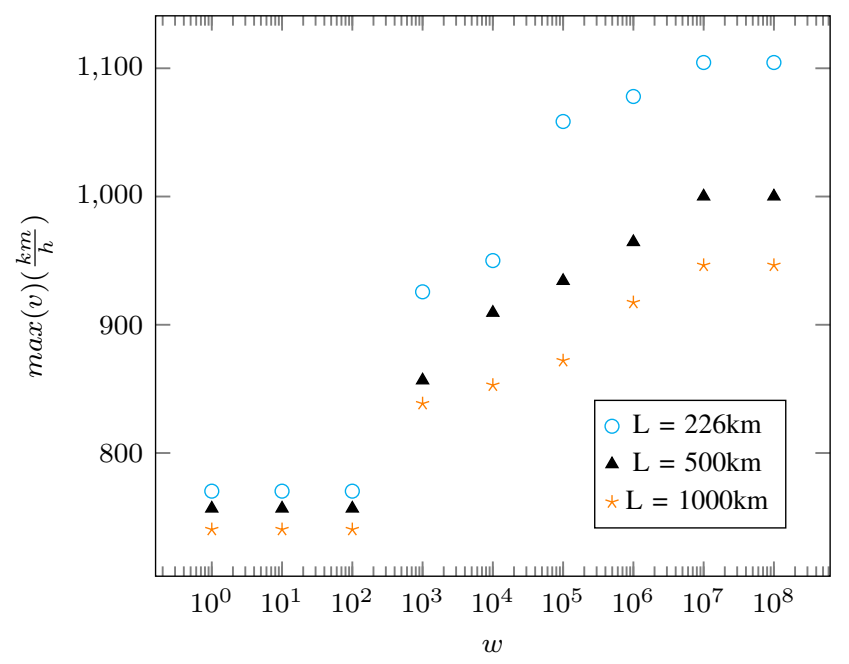

Fig. 10: Maximum speed along the trajectory.

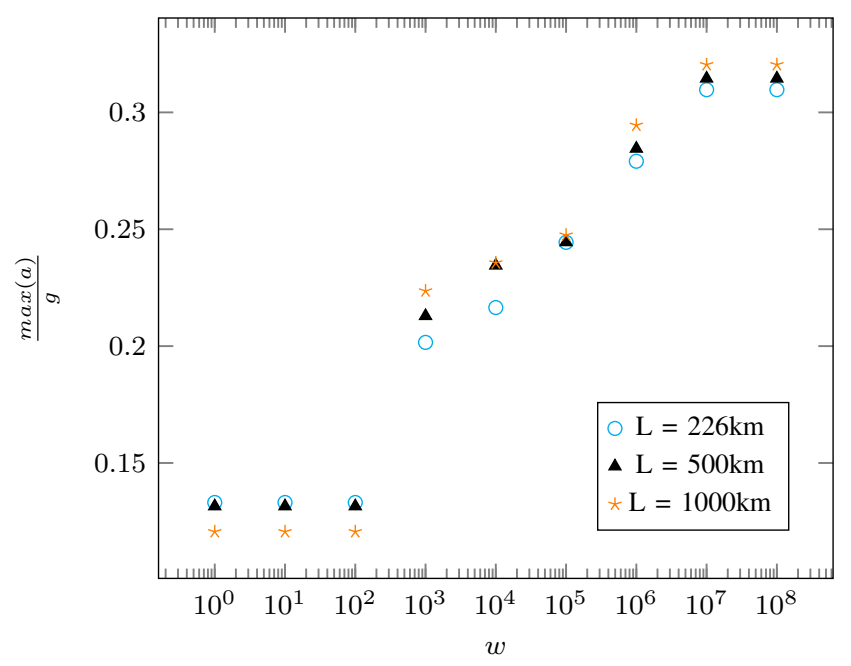

Fig. 11: Maximum acceleration along the trajectory (values in per-unit to $g$ ).

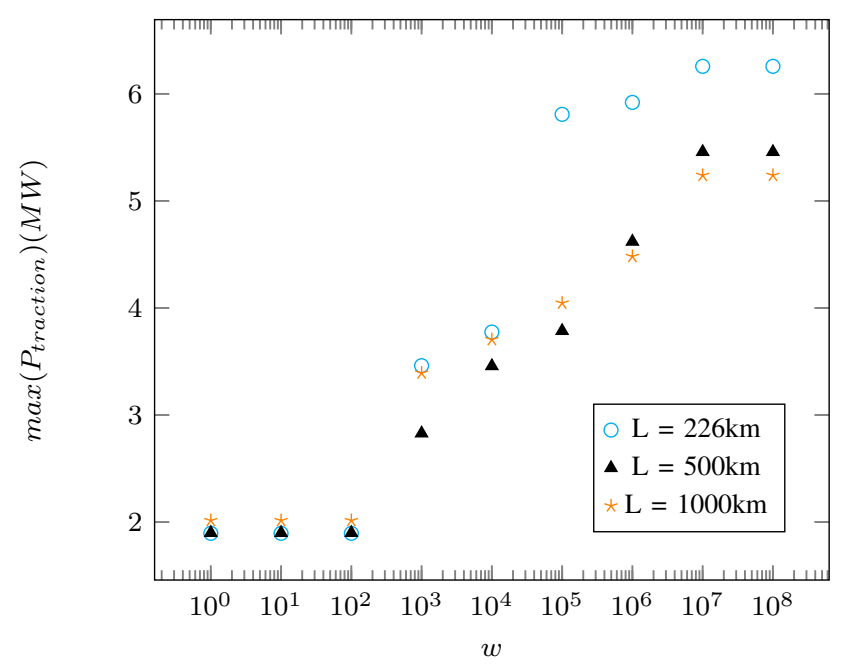

Fig. 12: Maximum traction power provided by the capsule PS along the trajectory.

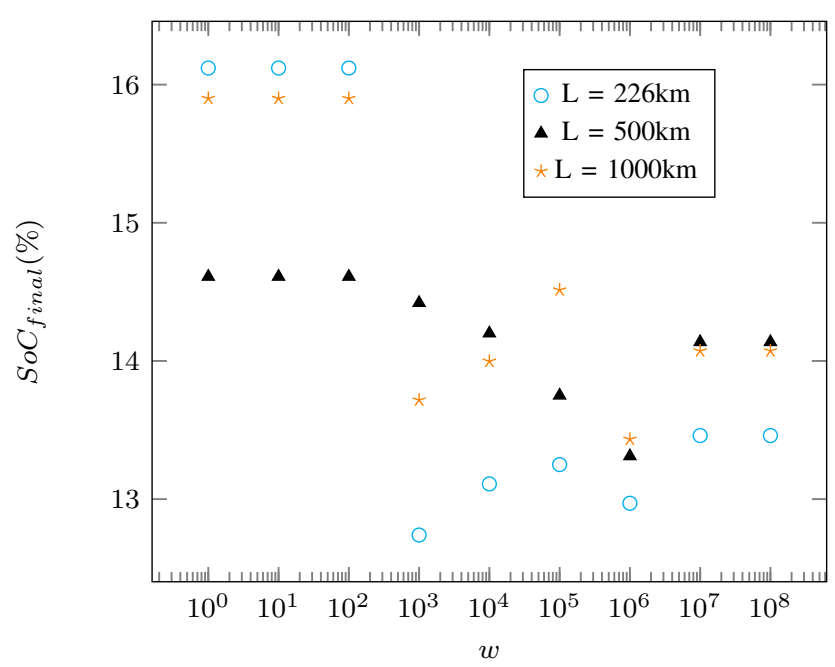

Fig. 13: BESS $S o C$ at the end of the trajectory.

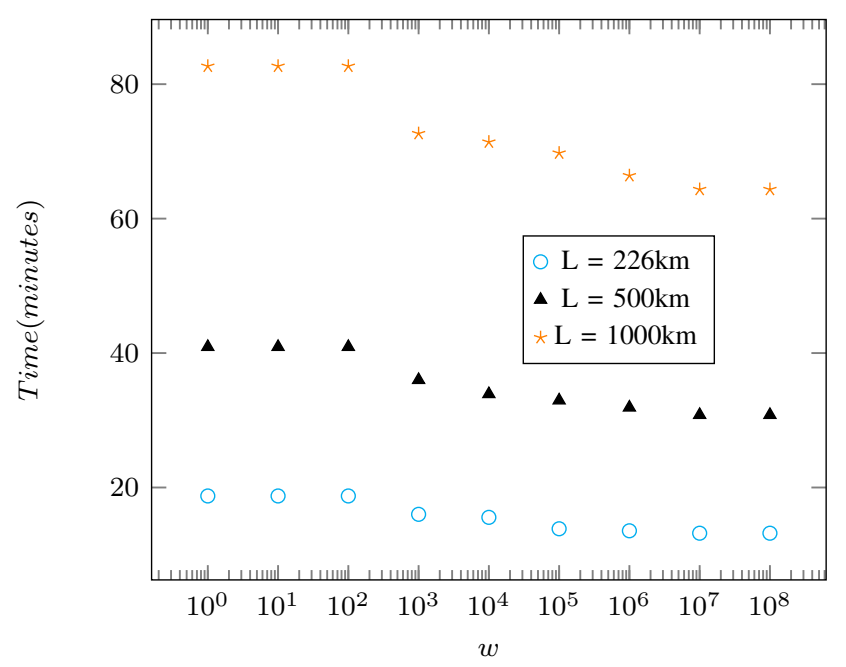

Fig. 14: Average time necessary to cover the trajectory. 


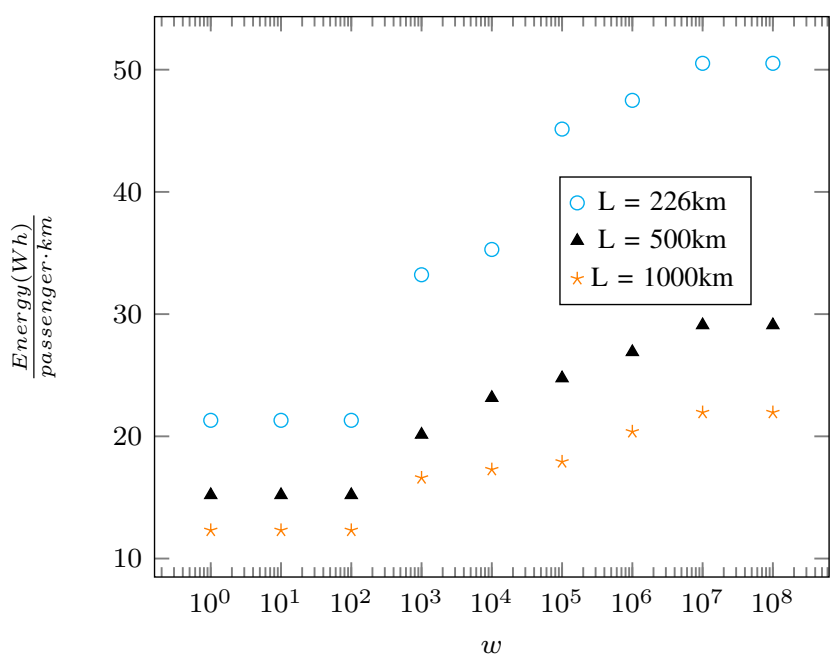

Fig. 15: The energy consumption per passenger per km.

$1000 \mathrm{~kg}, 1500 \mathrm{~kg}$ and $2500 \mathrm{~kg}$ for $L=226, L=500 \mathrm{~km}$, and $L=1000 \mathrm{~kg}$ respectively. The maximum capsule acceleration grows rapidly as $w$ increases up to a point where it saturates. Hence, for $w>10^{3}$, the maximum acceleration increases up to $0.3 \div 0.32 g$; this represents the maximum acceleration obtained for the considered cell and the assumptions on the capsule characteristics for three different lengths. The maximum instantaneous power is about $6.25 M W$ (for $L=226 \mathrm{~km}$ ) and $5.5 \mathrm{MW}$ (for $L=500 \mathrm{~km}$ and $L=1000 \mathrm{~km}$ ) for $w \in\left[10^{7}, 10^{8}\right]$ and is associated to a total number of cells of $N_{s} N_{p}=16468, N_{s} N_{p}=21122, N_{s} N_{p}=31862$. The maximum speed for the different lengths, $L=226 \mathrm{~km}$, $L=500 \mathrm{~km}, L=1000 \mathrm{~km}$ varies between $771 \frac{\mathrm{km}}{\mathrm{h}} \div 1104 \frac{\mathrm{km}}{\mathrm{h}}$, $757 \frac{\mathrm{km}}{\mathrm{h}} \div 1000 \frac{\mathrm{km}}{\mathrm{h}}$, and $740 \frac{\mathrm{km}}{\mathrm{h}} \div 946 \frac{\mathrm{km}}{\mathrm{h}}$ respectively. For larger distances, the optimal maximum-speeds intervals given by the minimum and maximum value of $w$ shrinks down due to the linear increase of the maximum travel time constraint and the longer zones travelled by the capsule at the maximum speed.

As already stated in Fig. 4, the minima of the objective function given in (14) for $w=100$ and $L=226 \mathrm{~km}$ is found for the following initialization: $a_{\text {init }}=0.6 \frac{\mathrm{m}}{\mathrm{s}^{2}}$ and $N_{s} N_{p, \text { init }}=$ 2000cells. In Fig. 5, the optimal-speed profile is shown, hence computed as a result of the optimal-acceleration profile solved in (14). The capsule achieves its maximum speed at $771 \frac{\mathrm{km}}{\mathrm{h}}$, and constantly runs at this speed, until the deceleration zone. The two different acceleration zones are clearly observed in Fig. 6, where the optimal-traction power profile is presented. Before achieving its peak of power, due to the two different acceleration zones (after $L_{1}=5 \mathrm{~km}$ ), and to the increase of speed, the traction profile exhibits a transition because of (13). The instantaneous power of the capsule substantially reduces once the maximum speed is achieved; and, due to the low-pressure atmosphere, even at high-speeds, the necessary amount of injected power to maintain the constant speed is low-relative to the maximum instantaneous power given by the acceleration zone. We present the current consumption for a given cell from the BESS in Fig. 7, as a result of (2). The profile of the current consumption for a single cell is similar to the profile of the power profile presented in Fig. 6, except for the constant-speed zone of the capsule. In this zone, due to the variation of the cell voltage with the SoC in (2), and in order to keep a constant power of the capsule, the current consumption slightly increases from the moment when the maximum speed is achieved until the braking zone. The peak of current consumption over the trajectory represents almost half of the maximum allowed discharge rate of the cell. The other optimal profiles for speed, traction power, cell current consumption look similar as the presented ones for every $w$ and $L$. However, due to the low-energy density of the cell, the solution of the optimization problem is constrainted by the level of $S o C$. For higher values of $w$, where the solution is represented by larger values of the instantaneous power of the capsule (Fig. 12), the solution of the problem is constrainted by the discharge rate of the cell and not by the level of $S o C$.

The identified Hyperloop PS solutions are feasible with the today's cell technology. In a range of $0.9 \div 2$ tones, $1.4 \div 2.7$ tones, respectively $2.3 \div 4$ tones of battery cells (Fig. 8 and Fig. 9), most of the mass is still distributed between the mechanical sub-systems and the payload. Another outcome is related to the level of the $S o C$. The problem has been constrainted for a minimum $S o C$ value of $10 \%$ before the regenerative braking zone. Therefore, all the available BESS energy is absorbed at the end of the constant-speed zone, and the level of $S o C$ tends to the minimum value imposed by the optimization problem. Due to the low charging rate of the cell $(1 C)$, compared with the discharge rate $(30 C)$, the level of $S o C_{\text {final }}$ presented in Fig. 13 does not reach high values.

In Fig. 14, the average traveling time stays in the range of $13 \div 19$ minutes, $31 \div 40$ minutes, respectively $65 \div$ 83 minutes, where the upper boundary of this range is governed by the lower values of $w(w=\{1,10,100\})$. Indeed, the average traveling time is related to the maximum speed over the trajectory given in Fig. 10, as a result of the acceleration profile, where every maximum point, with respect to $w$, can be found in Fig. 11 .

Irrespectively of the value of $w$, it is important to observe that the obtained BESS masses and the total number of cells are compatible with the currently proposed applications in commercial heavy-duty electric vehicles (e.g., electric trucks). The same observation applies to the maximum powers obtained for the other elements of the capsule propulsion. Therefore, the results indicate the technical feasibility of the identified capsule propulsion using today's technologies. To the best of the Authors' knowledge, this is the first paper in the literature that provides numerical support to this fundamental observation for the Hyperloop capsules PS design. With a battery-energy reservoir not larger than $10 M W$, Hyperloop can offer a transportation system for goods or people at speeds of $1000 \frac{\mathrm{km}}{\mathrm{h}}$ with accelerations comparable with the commercial aircrafts.

A final remark is about the estimation of the required energy $/ \mathrm{km} /$ passenger given in Fig. 15. This estimation refers only to the capsule's energy consumption and does not include the Hyperloop-tube vacuuming process. For this computation, the BESS charging efficiency is considered to be: $\eta_{\text {charging }}=$ $89.4 \%$ [42]- [44]. It is worth observing that, for the identified solution corresponding to $w=100$, we obtain values in the 
order of $22 \frac{\mathrm{Wh}}{\text { passenger } \cdot \mathrm{km}}$ for $L=226 \mathrm{~km}, 15.2 \frac{\mathrm{Wh}}{\text { passenger } \cdot \mathrm{km}}$ for $L=500 \mathrm{~km}$ and $12.3 \frac{\mathrm{Wh}}{\text { passenger } \cdot \mathrm{km}}$ for $L=1000 \mathrm{~km}$. The results show an interesting finding: for longer distances (i.e., $L=500 \mathrm{~km}$ and $L=1000 \mathrm{~km}$ ), the energy consumption per passenger per $\mathrm{km}$ is dropping down. This important compression of the average energy consumption is mostly influenced by the longer time spent by the capsule at the cruising speed where the power consumption of the capsule is flattened (and minimal).

The solutions corresponding to longer distances (i.e., $L=$ $500 \mathrm{~km}$ and $L=1000 \mathrm{~km}$ ) present similar maximum instantaneous power profiles (Fig. 12) even if they present different masses and different lengths. With similar acceleration profiles, the difference is made by the speed profiles and the time spent at the cruising speed, and the $S o C$ limitation which is directly influenced by the speed profile and mass of the capsule.

\section{E. Dominant Solutions}

For the sake of comparing the results, it is necessary to identify dominant solutions. The dominant solution for the capsule design can be determined by minimizing cost, power, and mass of the PS, while preserving similar capsule's performances. In this respect, the key performance indicator is given by the trajectory travel-time. Reducing the power of the PS implies both reducing its cost and mass and increasing the trajectory travel-time. Hence, the dominant solution can be determined by looking at the values assumed by the quantity $O_{1}=\frac{\max \left(P_{\text {traction }}\right)}{\text { TravelTime }}$. This auxiliary quantity helps us to identify a dominant solution (for the minimum value of $O_{1}$ ) that is for:

- $L=226 \mathrm{~km}$, for $w=100, O_{1}=0.101 \frac{\mathrm{MW}}{\mathrm{min}}$

- $L=500 \mathrm{~km}$, for $w=100, O_{1}=0.047 \frac{\mathrm{Mi}}{\mathrm{min}}$

- $L=1000 \mathrm{~km}$, for $w=100, O_{1}=0.025 \frac{\mathrm{min}^{\mathrm{m}} \mathrm{m}}{\mathrm{min}}$

We can consider another auxiliary quantity in order to identify a different dominant solution. This additional auxiliary quantity takes into consideration the energy consumption with respect to the travel time, hence we can define the auxiliary quantity $\mathrm{O}_{2}=\frac{\text { Energy }}{\text { Distance.Passenger.TravelTime }}$ which is minimal for:

- $L=226 \mathrm{~km}$, for $w=100, O_{2}=1.14 \frac{\mathrm{Wh}}{\mathrm{km} \cdot \text { passenger } \cdot \min }$

- $L=500 \mathrm{~km}$, for $w=100, O_{2}=0.371 \frac{\mathrm{Wh}}{\mathrm{km} \cdot \text { passenger } \cdot \min }$

- $L=1000 \mathrm{~km}$, for $w=100, \mathrm{O}_{2}=$ $0.149 \frac{\mathrm{Wh}}{\mathrm{km} \cdot \text { passenger } \cdot \min }$

These metrics enable us to conclude that for any different considered length, the optimal solution is found for $w=100$. These results are also similar with the one presented in the Results section. Namely, for a lower power sizing of the capsule's PS, lower energy consumption/passenger $/ \mathrm{km}$ and larger travel time, the $O_{1}$ and $O_{2}$ metric shrinks down.

\section{F. Sensitivity Analysis}

In the subsection discussing the dominant solutions, the solution corresponding to $w=100$ appears to represent the best trade-off between the performance and cost of the PS. In this subsection, we verify the sensitivity of this dominant solution with respect to the variations of parameters that might exhibit changes in the design stage of the capsule. We specifically refer to $k_{1}+k_{2}$ and $m_{0}$. The sensitivity analysis is carried out for $w=100$, by solving (14) varying $k_{1}+k_{2}$ and $m_{0}$ above their initial values. The ranges of these parameters used in this analysis are $\left(k_{1}+k_{2}\right)_{\text {init }} \rightarrow 2\left(k_{1}+k_{2}\right)_{\text {init }}$ and $m_{0, \text { init }} \rightarrow \frac{5}{4} \cdot m_{0, \text { init }}$. Fig. 16 and Fig. 17 show the modifications of the BESS total number of cells and trajectory travel time. As it can be seen from these two figures, the solutions vary in a continuous way. For the largest values of $\left(k_{1}+k_{2}\right)$ and $m_{0}$ with a fixed length of trajectory, $L=226 \mathrm{~km}$, the average traveling time is reduced by one minute (i.e., 5\%), with respect to the value obtained with the original solution. This result is due to an increase of the BESS number of cells in the range of $10 \%$, with respect to the original optimal solution.

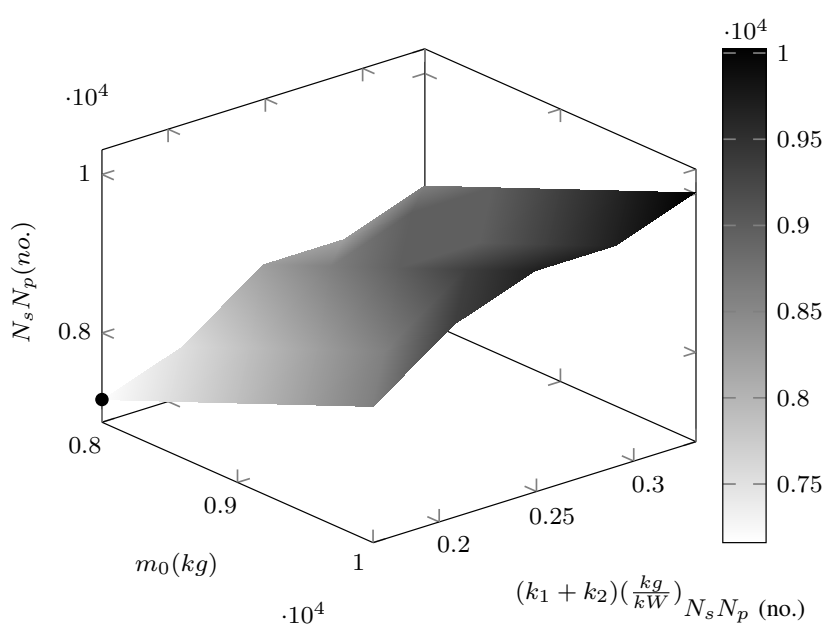

Fig. 16: Number of cells sensitivity analysis (for $w=100$ ).

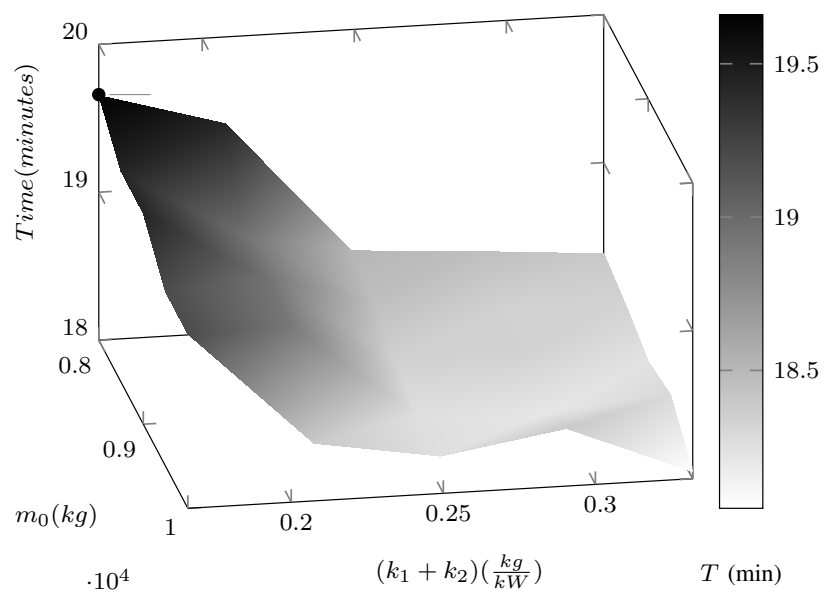

Fig. 17: Trajectory traveling time sensitivity analysis (for $w=100)$. 


\section{CONCLUSIONS}

In this paper, we have proposed a specific optimization problem for the design of the PS of a Hyperloop capsule. The problem's objective-function is composed of the number of cells of the BESS that supply the capsule propulsion and the performance of the capsule given by the norm-2 of the array of the space-discretized accelerations along the capsule trajectory. The constraints rely on numerically tractable models of the three elements composing such a PS, as well as the kinematic model of the capsule.

A comprehensive analysis of the results is given for the different weights of the terms in the objective function. The analysis of the results demonstrates the technical feasibility of the Hyperloop PS, with respect to existing BESS and electrical propulsion technologies. Furthermore, the proposed design method enables to compute energy consumption of the capsule's propulsion between 10 to $50 \mathrm{Wh} / \mathrm{km} /$ passenger depending on the assumptions and trajectory parameters. With the proposed sizing method and Hyperloop capsule architecture, we conclude that today's battery and power-electronics technologies exhibit characteristics that are compatible with the Hyperloop application, thus enable its development as a viable transportation solution.

Hyperloop can represent an intra-continental transportation solution that can complement, or replace, travel via plane and train. For example, on the considered route between the two strongest economic poles of Switzerland, there are more than half of a million travelers reported yearly. Hyperloop can be considered a complementary mode of transportation, which could efficiently sustain this point-to-point travels.

The Hyperloop industry is still in its infancy. To the best of our knowledge, this is the first paper that provides a numerical support of the design of a Hyperloop capsule's PS. Future work will cover a more comprehensive modeling for the BESS and PS and their inclusion in the proposed optimization framework.

\section{REFERENCES}

[1] J. Becker, T. Nemeth, R.Wegmann and D. U. Sauer, "Dimensioning and Optimization of Hybrid Li-Ion Battery Systems for EVs," in World Electric Vehicle Journal June 2018.

[2] B. Bilgin et al., "Making the Case for Electrified Transportation," in IEEE Transactions on Transportation Electrification, vol. 1, no. 1, pp. 4-17, June 2015.

[3] Y.F. Wang, K.P. Li, X.M. Xu, Y.R. Zhang, ’Transport energy consumption and saving in China," in Renewable and Sustainable Energy Reviews 29 (2014) 641-655.

[4] K. Ruangjirakit, Y. Laoonual, A. Charadsuksawat, V. Kiattikomol and S. Sridan, "A Study of Grid-to-Wheel Energy Consumption of Electric Vehicle on Real Road Tests in Bangkok,' 2018 IEEE Transportation Electrification Conference and Expo, Asia-Pacific (ITEC Asia-Pacific), Bangkok, 2018, pp. 1-5.

[5] The International Council on Clean Transportation, "Effects of battery manufacturing on electric vehicle life-cycle greenhouse gas emissions," Technical Report, [online] www.theicct.org, February 2018.

[6] E. Andersson, P. Lukaszewicz, "Energy consumption and related air pollution for Scandinavian electric passenger trains," Technical Report, [online] https://www.kth.se/polopoly_fs/1.179879.1397142793!/Menu/ general/column-content/attachment/Energy_060925_full_pdf.pdf, 2006.
[7] International Union of Railways, "Technologies and Potential Developments for Energy Efficiency and $\mathrm{CO}_{2}$ Reductions in Rail Systems," Technical Report, [online] https://uic.org/IMG/pdf/_27_ technologies_and_potential_developments_for_energy_efficiency_and_ co2_reductions_in_rail_systems._uic_in_colaboration.pdf, December $201 \overline{6}$.

[8] Spacex, "Hyperloop Alpha," Technical Report, [online] https:// www.spacex.com/sites/spacex/files/hyperloop_alpha-20130812.pdf, August 2013.

[9] SpaceX, "SpaceX Hyperloop Pod Competition Rules," January 2016.

[10] V. Madonna, P. Giangrande and M. Galea, 'Electrical Power Generation in Aircraft: Review, Challenges, and Opportunities," in IEEE Transactions on Transportation Electrification, vol. 4, no. 3, pp. 646-659, Sept. 2018.

[11] F. Akar, Y. Tavlasoglu and B. Vural, ”An Energy Management Strategy for a Concept Battery/Ultracapacitor Electric Vehicle With Improved Battery Life," in IEEE Transactions on Transportation Electrification, vol. 3, no. 1, pp. 191-200, March 2017.

[12] B. Sarlioglu and C. T. Morris, "More Electric Aircraft: Review, Challenges, and Opportunities for Commercial Transport Aircraft," in IEEE Transactions on Transportation Electrification, vol. 1, no. 1, pp. 54-64, June 2015.

[13] R. C. Kroeze and P. T. Krein, 'Electrical battery model for use in dynamic electric vehicle simulations," 2008 IEEE Power Electronics Specialists Conference, Rhodes, 2008, pp. 1336-1342.

[14] K. Wipke, T. Markel and D. Nelson, "Optimizing Energy Management Strategy and Degree of Hybridization for a Hydrogen Fuel Cell SUV,' in Proceedings of 18th Electric Vehicle Symposium, Berlin, 2001.

[15] K. Dominik, H. Chris and R. Aymeric,2008, "Impact of Component Size on Plug-In Hybrid VehicleEnergy Consumption Using Global Optimization",The World Electric Vehicle Journal, vol.2, no.2.

[16] A. González-Gil, R. Palacin, P. Batty, J.P. Powell, ”A systems approach to reduce urban rail energy consumption," in Energy Conversion and Management 80 (2014) 509-524.

[17] D. Zhao, R. Stobart, G. Dong and E. Winward, "Real-Time Energy Management for Diesel Heavy Duty Hybrid Electric Vehicles," in IEEE Transactions on Control Systems Technology, vol. 23, no. 3, pp. 829-841, May 2015.

[18] Huilong Yu, F. Castelli-Dezza and F. Cheli, "Optimal powertrain design and control of a 2-IWD electric race car," 2017 International Conference of Electrical and Electronic Technologies for Automotive, Torino, 2017, pp. 1-7.

[19] A. González-Gil, R. Palacin, P. Batty, "Optimal energy management of urban rail systems: Key performance indicators," in Energy Conversion and Management 90 (2015) 282-291.

[20] Y. Cao, R. C. Kroeze and P. T. Krein, "Multi-timescale Parametric Electrical Battery Model for Use in Dynamic Electric Vehicle Simulations," in IEEE Transactions on Transportation Electrification, vol. 2, no. 4, pp. 432-442, Dec. 2016.

[21] J. Park, Y. L. Murphey and M. Abul Masrur, "Intelligent Energy Management and Optimization in a Hybridized All-Terrain Vehicle With Simple On-Off Control of the Internal Combustion Engine," in IEEE Transactions on Vehicular Technology, vol. 65, no. 6, pp. 4584-4596, June 2016.

[22] B. Y. Liawa, G. Nagasubramanianb, R. G. Jungstc, D. H. Doughtyb, "Modeling of lithium ion cells-A simple equivalent-circuit model approach," in Solid State Ionics 175 (2004) 835-839.

[23] G. Joos, M. de Freige and M. Dubois, "Design and simulation of a fast charging station for PHEV/EV batteries,' 2010 IEEE Electrical Power and Energy Conference, Halifax, NS, 2010, pp. 1-5.

[24] S. Santhanagopalan, Q. Guo, P. Ramadass, and R. E. White. "Review of models for predicting the cycling performance of lithiumion batteries," in Journal of Power Sources, 156(2):620-628, 2006.

[25] M. R. Jongerden and B. R. Haverkort. "Which battery model to use?," in IET software, 3(6):445-457, 2009.

[26] M. Einhorn, F. V. Conte, C. Kral and J. Fleig, "Comparison, Selection, and Parameterization of Electrical Battery Models for Automotive Applications," in IEEE Transactions on Power Electronics, vol. 28, no. 3, pp. 1429-1437, March 2013.

[27] D. W. Dees, V. S. Battaglia and A. Bélanger, "Electrochemical modeling of lithium polymer batteries," in Journal of Power Sources 110 (2002) 310-320.

[28] C. Zhao, H. Yin, Z. Yang and C. Ma, "Equivalent Series ResistanceBased Energy Loss Analysis of a Battery Semiactive Hybrid Energy Storage System," in IEEE Transactions on Energy Conversion, vol. 30, no. 3, pp. 1081-1091, Sept. 2015. 
[29] E. E. Dudnikov, "Advantages of a new Hyperloop transport technology," 2017 Tenth International Conference Management of Large-Scale System Development (MLSD), Moscow, 2017, pp. 1-4.

[30] W. Ji, G. Jeong, C. Park, I. Jo and H. Lee, "A Study of Non-Symmetric Double-Sided Linear Induction Motor for Hyperloop All-In-One System (Propulsion, Levitation, and Guidance)," in IEEE Transactions on Magnetics, vol. 54, no. 11, pp. 1-4, Nov. 2018, Art no. 8207304.

[31] H. Cho, Y. Liu and K. A. Kim, "Short-Primary Linear Induction Motor Modeling with End Effects for Electric Transportation Systems," 2018 International Symposium on Computer, Consumer and Control (IS3C), Taichung, Taiwan, 2018, pp. 338-341.

[32] A. E. Hodaib, S. F. A. Fattah, "Conceptional Design of a Hyperloop Capsule with Linear Induction Propulsion System," World Academy of Science, Engineering and Technology International Journal of Aerospace and Mechanical Engineering Vol:10, No:5, 2016.

[33] T. Nemeth, A. Bubert, J. N. Becker, R. W. De Doncker and D. U. Sauer, "A Simulation Platform for Optimization of Electric Vehicles With Modular Drivetrain Topologies," in IEEE Transactions on Transportation Electrification, vol. 4, no. 4, pp. 888-900, Dec. 2018.

[34] Liversage, P., and Trancossi, M., "Analysis of triangular sharkskin profiles according to second law," Modelling, Measurement and Control B. 87(3), 188-196, September 2018.

[35] İ. Şengör, H. C. Kılıçkıran, H. Akdemir, B. Kekezogcaronlu, O. Erdinç and J. P. S. Catalão, ”Energy Management of a Smart Railway Station Considering Regenerative Braking and Stochastic Behaviour of ESS and PV Generation," in IEEE Transactions on Sustainable Energy, vol. 9, no. 3, pp. 1041-1050, July 2018.

[36] S. Heydari, P. Fajri, M. Rasheduzzaman and R. Sabzehgar, "Maximizing Regenerative Braking Energy Recovery of Electric Vehicles Through Dynamic Low-Speed Cutoff Point Detection," in IEEE Transactions on Transportation Electrification, vol. 5, no. 1, pp. 262-270, March 2019.

[37] Byrd, R. H., J. C. Gilbert, and J. Nocedal. "A Trust Region Method Based on Interior Point Techniques for Nonlinear Programming." Mathematical Programming, Vol 89, No. 1, 2000, pp. 149-185.

[38] Byrd, R. H., Mary E. Hribar, and Jorge Nocedal. "An Interior Point Algorithm for Large-Scale Nonlinear Programming." SIAM Journal on Optimization, Vol 9, No. 4, 1999, pp. 877-900.

[39] Bombardier CRJ-1000 Aircraft, "CRJ Series," Technical Report, [online] https://commercialaircraft.bombardier.com/themes/bca/pdf/ Bombardier_CRJ_Series_Brochure.pdf, 2017.

[40] Max M. J. Opgenoord and Philip C. Caplan, "Design of the Hyperloop Concept," AIAA Journal 2018 56:11, 4261-4270.

[41] "IEC 60850:2014 International Electrotechnical Commission-Railway applications - Supply voltages of traction systems," November 2014.

[42] J. Sears, D. Roberts and K. Glitman, "A comparison of electric vehicle Level 1 and Level 2 charging efficiency," 2014 IEEE Conference on Technologies for Sustainability (SusTech), Portland, OR, 2014, pp. 255258.

[43] K. Knezović, S. Martinenas, P. B. Andersen, A. Zecchino and M. Marinelli, "Enhancing the Role of Electric Vehicles in the Power Grid: Field Validation of Multiple Ancillary Services," in IEEE Transactions on Transportation Electrification, vol. 3, no. 1, pp. 201-209, March 2017.

[44] R. Xie, W. Wei, M. E. Khodayar, J. Wang and S. Mei, "Planning Fully Renewable Powered Charging Stations on Highways: A Data-Driven Robust Optimization Approach," in IEEE Transactions on Transportation Electrification, vol. 4, no. 3, pp. 817-830, Sept. 2018.

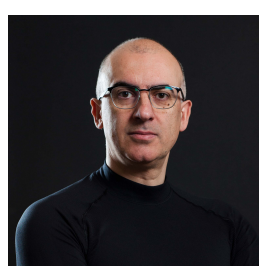

Mario Paolone (M'07, SM'10) received the M.Sc. (with Hons.) and Ph.D. degrees in electrical engineering from the University of Bologna, Italy, in 1998 and 2002, respectively. In 2005, he was appointed Assistant Professor in power systems with the University of Bologna, where he was with the power systems laboratory until 2011. In 2010, he received the Associate Professor eligibility from the Polytechnic of Milan, Italy. Since 2011, he joined the Swiss Federal Institute of Technology, Lausanne, Switzerland, where he is currently Full Professor,

Chair of the Distributed Electrical Systems Laboratory, Head of the Swiss Competence Center for Energy Research Future Swiss Electrical infrastructure and Chair of the EPFL Energy Centre Directorate. He has authored or coauthored over 300 papers published in mainstream journals and international conferences in the area of energy and power systems. His research interests focus on power systems with particular reference to real-time monitoring and operation aspects, power system protections, dynamics and transients. Dr. Paolone is the Editor-in-Chief of the Elsevier journal Sustainable Energy, Grids and Networks.

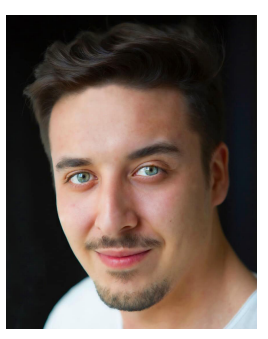

Denis Tudor received the B.Sc. (Valedictorian) degree in electronic engineering from the Polytechnic University of Bucharest, Romania in 2017. He is currently pursuing the Ph.D. degree with the Distributed Electrical System Laboratory, Swiss Federal Institute of Technology of Lausanne, Lausanne, Switzerland. His research interests include the development of optimal design and operation strategies of Hyperloop transportation system. 